\title{
Physicochemical characterization and antioxidant activity of honey with Eragrostis spp. pollen predominance
}

\author{
Smail Aazza ${ }^{1}$ | Youssef Elamine ${ }^{1}$ | Soukaïna El-Guendouz ${ }^{1}$ | Badiâa Lyoussi ${ }^{1}$ |

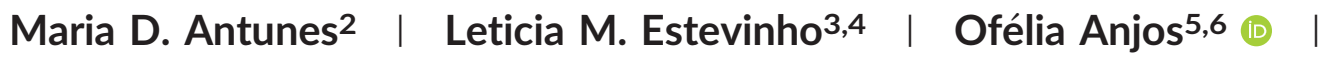 \\ Jorge D. Carlier ${ }^{7}$ | Maria C. Costa7 | Maria G. Miguel² 이 \\ ${ }^{1}$ Laboratory of Physiology-Pharmacology-Environmental Health, Faculty of Sciences Dhar El Mehraz, BP 1796 Atlas, University Sidi Mohamed Ben Abdallah, \\ Fez 30 000, Morocco \\ ${ }^{2}$ Universidade do Algarve, FCT, MeditBio, Edf 8, Campus de Gambelas 8005-139 Faro, Portugal \\ ${ }^{3}$ Departamento de Biologia e Biotecnologia, Escola Superior Agrária, Instituto Politécnico de Bragança, Campus Santa Apolónia, Apartado 1172, Bragança 5301-855, \\ Portugal \\ ${ }^{4}$ Centre of Molecular and Environmental Biology, University of Minho, Campus de Gualtar, Braga, Portugal \\ 5IPCB - Instituto Politécnico de Castelo Branco, Castelo Branco 6001-909, Portugal \\ ${ }^{6}$ Centro de Estudos Florestais, Instituto Superior de Agronomia, Universidade de Lisboa, Tapada da Ajuda, Lisboa 1349-017, Portugal \\ ${ }^{7}$ Centro de Ciências do Mar, Universidade do Algarve, FCT, Campus de Gambelas, Faro 8005-139, Portugal
}

\section{Correspondence}

Maria G. Miguel, Universidade do Algarve, FCT, MeditBio, Edf 8, Campus de Gambelas 8005-139 Faro, Portugal.

Email: mgmiguel@ualg.pt

Funding information

Portuguese National Funding Agency for Science, Research and Technology (Fundação para a Ciência e a Tecnologia FCT), Grant/Award Number: UID/AGR/ 00239-2013, UID/BIA/04325/2013 MEDTBIO, UID/Multi/04326/2013 and UID/BIA/04050/2013

\begin{abstract}
This study aimed to characterize the pollen and physicochemical profiles, and to evaluate the antioxidant capacity of six samples of Moroccan honey. The pollen grains of Eragrostis spp. were predominant in all samples (from a minimum of $46.58 \pm 1.59 \%$ to $72.72 \pm 2.43 \%$ as a maximum), exceeding the minimum (generally $45 \%$ ) required for the monoflorality nomination of a honey sample, and suggestion a case of newly reported honey. The analyzed samples had low diastase activity and hydroxymethylfurfural (HMF) content. Potassium was the dominant element in practically all samples, except the sample with the highest Eragrostis spp. pollen percentage, which showed sodium predominance. The honey color ranged from water white to light amber, and positively correlated the concentrations of phenols, proline and the capacity for scavenging free radicals. However, great variability observed in all the analyzed parameters, and could not be explained by the variability of the Eragrostis spp. pollen percentage, which suggests a hypothesis of low concentrated nectar.
\end{abstract}

\section{Practical applications}

The melissopalynological profile of honey is an important parameter for determining the type of honey (multifloral, monofloral, blossom, honeydew) and its relationship to the botanical and geographical provenance. There is generally a relationship between the pollen profile of honey and the biological properties. The physicochemical characterization, antioxidant activity and melissopalynological profile of Eragrostis honey was reported for the first time in this study. These data intend to contribute for the introduction of a new type of honey labeled as Eragrostis honey. At the same time, the evaluation of the antioxidant activity may also trigger the search of other biological properties with medicinal attributes for the new Eragrostis ssp. honey.

KEYWORDS

food quality, melanoidins, natural antioxidants 


\section{INTRODUCTION}

Beekeeping in Morocco is one of the most important economical activities, being the current annual honey production about 2,500-3,500 tons. According to the estimations of the Ministry of Agriculture, Rural Development and Maritime Fisheries, which is making major efforts to modernize the sector and assist beekeepers, honeys' production may reach 16,000 tones by 2020 (Moujanni, Essamadi, \& Terrab, 2017). Even so, despite the great potentiality of this sector, it is feared that honey's production may stagnate due to difficulties concerning repopulating colonies and the lack of scientific studies that characterize the product and ensure its good quality, safety and allow assessing their biological activities and, therefore, expanding the range of applications.

Even though the legislation regarding honey production and trading in Morocco is scarce, the European legislation establishes, since 1995 , that the labeling of the floral origin of honey is essential to protect consumers and marketers [Council Directive EEC/74/409 amended by the Proposal COM/95/0722 (1996)]. It is, therefore, important to develop scientific tools to assess the floral origins of honey and/or the presence of any adulteration in samples. Indeed, melissopalynology provides information on the melliferous plants yet there is no correlation between a pollen count and the quantity of the delivered nectar. This gives rise to the problematic of the minimum pollen required for the monoflorality nomination. In the case of Lavandula spp., as an example of a strong nectar delivering plant, the presence of $15 \%$ of its pollen in a honey sample is sufficient to obtain the lavender monoflorality nomination. In contrast Castanea spp. needs to be represented by more than $90 \%$ of total pollen content to provide the monoflorality of a honey sample (Gomes, Dias, Moreira, Rodrigues, \& Estevinho, 2010). Due to these limitations other characteristics, like the physicochemical parameters, are also essential to ascertain the botanical origin of honey and are widely used in routine honey analysis (Elamine et al., 2017).

The above-mentioned interest came, mainly, from the rich chemical composition of honey (carbohydrates, proteins, enzymes free amino acids, essential minerals, vitamins, and polyphenols), which makes it an important source of bioactive compounds responsible for several biological activities including antioxidant, anti-inflammatory, antimicrobial, anti-ulcer, antihyperlipidemic, antidiabetic, and anticancer properties (Alvarez-Suarez, Giampieri, \& Battino, 2013).

These beneficial properties, particularly antioxidant, are due to the presence of a great variety of compounds like phenolic acids (ellagic, caffeic, $p$-coumaric and ferulic acids), ascorbic acid, flavonoids (apigenin, pinocembrin, kaempferol, quercetin, galangin, chrysin, and hesperetin), tocopherols, enzymes (catalase, superoxide dismutase), reduced glutathione, amino acids and carotenoids (Almeida-Muradian, Stramm, \& Estevinho, 2014; Rao et al., 2016).

It is important to consider that honey's physicochemical characteristics are strongly related to the botanical source of the nectar, which determines the content of secondary metabolites (El-Sohaimy, Masry, \& Shehata, 2015; Silva et al., 2013), but also to the climatic conditions of the locations where the beehives are placed.
Therefore, the present work aimed at the characterization of a Moroccan honey with predominance of Eragrostis spp. pollen, regarding its physicochemical characteristics and antioxidant activity. The results showed high variability among the analyzed samples, with low contribution of Eragrostis spp. pollen presence.

\section{2 | MATERIAL AND METHODS}

\section{$2.1 \mid$ Reagents and solvents}

$\mathrm{NaOH}, \mathrm{Na}_{2} \mathrm{CO}_{3}$, sodium phosphate were purchased from Pronalab, Madalena, Portugal; $\mathrm{HCl}$ was purchased from Fisher Scientific UK Ltd.; Loughborough, UK; $\mathrm{KCl}$ was purchased from BHD Prolabo; Leuven, Belgium; acetic acid, ascorbic acid, Folin-Ciocalteu, fuchsin, $\mathrm{KOH}$, methanol, 2-propanol were purchased from Merck KGaA; Darmstadt, Germany; 2,2-azino-bis(3- ethylbenzothiazoline-6-sulphonic acid) (ABTS), ferrozine, $\mathrm{FeSO}_{4}$, gallic acid, NBT, ninhydrine, PMS, proline were purchased from Acros Organics; $\mathrm{NJ} ; \mathrm{AlCl}_{3}$ and anhydride acetic were purchased from Panreac Quimica, Montcada i Reixac; Barcelona, Spain; catechin was purchased from Fluka; glucose, fructose, sucrose, were purchased from Sigma Aldrich; $\mathrm{H}_{2} \mathrm{SO}_{4}$, sodium acetate, starch, potassium iodide, $\mathrm{I}_{2}$, sodium nitroprusside (SNP), were purchased from Riedel-deHaen; Germany; acetic acid was purchased from CHEM-Lab, Belgium.

\section{2 | Sampling}

The six honey samples $(n=6)$ harvested in 2013 were directly purchased from Moroccan beekeepers of the Tiznit region, in the southern Moroccan region of Souss-Massa. The samples were centrifuged on arrival at the laboratory, wrapped in aluminum for light protection, and stored at $4^{\circ} \mathrm{C}$ until analysis, which was about one month later.

\section{3 | Melissopalynological analysis}

The honey samples pollen qualitative and quantitative spectrum analysis was carried out according to the International Commission for Bee Botany (ICBB), as previously described (Louveaux, Maurizio, \& Vorwohl, 1978) and using an optic microscope (Leitz Messtechnik GmbH; Wetzlar, Germany). Reference standards obtained from Portugal honey flora were used for grain identification, and the classes were determined as follows: dominant pollen ( $>45 \%$ of a specific pollen type), secondary pollen (16-45\%), important minor pollen (3-15\%), and minor pollen (<3\%).

\section{4 | Physicochemical analysis}

Free acidity, $\mathrm{pH}$, lactone acidity, ash content, water content, electrical conductivity, proline, diastase activity, HMF were performed according to the harmonized method (Bogdanov, 2002).

\subsection{Estimation of honey color, and melanoidins content}

The determination of the honey color was carried out by measuring the absorbance at $635 \mathrm{~nm}\left(A_{635}\right)$ of an aqueous solution containing 
$10 \mathrm{~g}$ of honey and $20 \mathrm{~mL}$ of water, using a UV/Vis Shimadzu (Tokyo, Japan) spectrophotometer (Naab, Tamame, \& Caccavari, 2008). The absorbance values were converted on to the Pfund Scale through the equation: $\mathrm{mm}$ Pfund $=-38.70+371.39 \times A_{635}$. Additionally, color was determined by spectrophotometry by calculating net absorbance $\left(A_{560}-A_{720}\right)$.

The determination of honey melanoidin content was carried out based on the browning index (net absorbance $=A_{450}-A_{720}$ ) (Brudzynski $\&$ Miotto, 2011). Spectrophotometric measurements were performed in a $1 \mathrm{~cm}$ quartz cell and results were expressed as absorbance units $(\mathrm{AU})$.

\subsection{Sugars content}

Fructose, glucose and sucrose contents were evaluated according to the method described by Anjos, Campos, Ruiz, and Antunes (2015).

\section{7 | Polyphenols content}

The total phenol content was determined using the Folin-Ciocalteau method, with some modifications (Singleton \& Rossi, 1965) and the results were expressed as $\mathrm{mg}$ gallic acid equivalents (GAE)/100 g. In brief, $5 \mathrm{~g}$ of honey were treated with $10 \mathrm{~mL}$ of distilled water, mixed and centrifuged. Five hundred microliters of this solution was mixed with $2.5 \mathrm{~mL}$ Folin-Ciocalteau reagent $(0.2 \mathrm{~N})$ for $5 \mathrm{~min}$ and then $2 \mathrm{~mL}$ of a $\mathrm{Na}_{2} \mathrm{CO}_{3}$ solution added $(75 \mathrm{~g} / \mathrm{L})$. All samples were incubated at room temperature in the dark for $2 \mathrm{hr}$ and their absorbance was read at $760 \mathrm{~nm}$. The blank solution contained water instead of honey. To obtain the calibration curve, a stock solution of gallic acid $(1 \mathrm{mg} / \mathrm{mL})$ was prepared for further dilutions $(8-250 \mu \mathrm{g} / \mathrm{mL})$. As reducing sugars can interfere in this reaction, an artificial sugar solution was made according to the sugar profile of each sample, and used to remove the interference (Elamine et al., 2017).

\section{8 | Flavonoids content}

The flavonoid content (FC) of the different honey samples was quantified using the aluminum chloride assay through colorimetric method (Samatha, Shyamsundarachary, Srinivas, \& Swang, 2012). Possible interaction of sample color with the reaction reagents was avoided using a blank with water (substituting the other reaction components) and the sample as described by Sancho et al. (2016). The FC was expressed in $\mathrm{mg}$ of catechin equivalents (CE) per $100 \mathrm{~g}$ of honey.

\section{9 | Minerals content}

To analyze the mineral content, samples ( $5 \mathrm{~g}$ ) were subjected to calcination $\left(550^{\circ} \mathrm{C}\right)$. After cooling, the residue was placed in a desiccator for further analysis. Nitric acid $(5 \mathrm{~mL})$ was added to the ash and the mixture was stirred on a heating plate to almost complete dryness. Then, nitric acid $(10 \mathrm{~mL})$ was added and the mixture was brought up to $25 \mathrm{~mL}$ with distilled water. Afterwards, the mineral content was determined by flame atomic absorption ( $\mathrm{Ca}, \mathrm{Mg}, \mathrm{Mn}, \mathrm{Zn}, \mathrm{Cu}$, and $\mathrm{Fe}$ ) or emission ( $\mathrm{Na}, \mathrm{K}$ ) spectrometry (air-acetylene) using a novAA 350
(Analytik Jena, Germany). Results were expressed as milligrams of mineral content per kilogram of honey.

\section{$2.10 \mid$ Antioxidant activity}

This antioxidant activity was studied using four methodologies since the use of more than one method has been recommended, as such at least two methods must be performed (Sakanaka \& Ishihara, 2008). All measurements described in this section were performed in triplicate. The determination of ABTS (2,2'-azino-bis(3-ethylbenzothiazoline-6sulphonic acid) radical scavenging activity, and ferrous ions chelating effect were carried out as reported previously (Miguel, Nunes, Dandlen, Cavaco, \& Antunes, 2010). As for the determination of DPPH and superoxide anion scavenging activities, protocols were detailed by BrandWilliams, Cuvelier, and Berset (1995), and Soares (1996), respectively.

\subsection{1 | Statistical analysis}

Statistical analysis was carried out by ANOVA through the SPSS 22.0 program (SPSS Inc., Chicago, IL) and using the Tukey post hoc test at $p<.05$. Correlations between phenol, flavonoid, proline, melanoidins contents, color, and antioxidant activity were achieved by Pearson correlation coefficient $(r)$ at a significance level of $99 \%(p<.01)$. Principal component analyses (PCA) were performed with Minitab 17.1.0. (Minitab Inc., State College, PA, USA).

\section{3 | RESULTS AND DISCUSSION}

\section{1 | Melissopalynological analysis}

The melissopalynological analysis is currently the only technique allowing for the direct assessment of the botanical and geographic origin of honey (El-Sohaimy et al., 2015).

The percentages of the pollen types identified in the six Moroccan honeys are presented in Table 1 . The results show that in all samples, pollen grains of Eragrostis spp. predominated, ranging from $46.58 \pm$ $1.59 \%$, in sample $S 4$, to $79.67 \pm 1.82 \%$, in sample $S 6$, exceeding the minimal pollen percentage $(45 \%)$ required to declare honey monoflorality, and suggesting that the analyzed sample are Eragrostis spp. monofloral honey. The last claim needs to be further studied due to the exceptions reported by some authors: chestnut honey needs $90 \%$ of Castanea spp. pollen to be monofloral, and lavender honey needs only $15 \%$ of Lavandula spp. pollen (Gomes et al., 2010). Cardus spp. and Olea spp. are other pollen grains also detected, being the secondary pollens in sample S4 (22.39 $\pm 0.99 \%$ and $16.76 \pm 1.45 \%$, respectively) and only an important minor pollen in sample S6 $(9.05 \pm 1.57 \%$ and $7.85 \pm 0.13 \%$, respectively) (Table 1 ). The secondary pollen grains in samples S1, S2 and S3 were Cardus spp. (17.85 $\pm 0.93 \%)$, Phoenix spp. (22.19 $\pm 2.28 \%)$, and Thymus spp. (19.28 $\pm 1.65 \%)$, respectively.

\section{2 | Physicochemical characteristics}

The values of $\mathrm{pH}$ ranged from 3.57 , in $\mathrm{S} 3$, to 3.76 , in S2 (Table 2), which were inferior to those reported by some authors for Moroccan 
TABLE 1 Sample code, places of collection, year of production, and the most predominant pollen of six Eragrostis spp. honey samples from Morocco

\begin{tabular}{|c|c|c|c|c|}
\hline \multirow[b]{2}{*}{ Sample code } & \multirow[b]{2}{*}{ Eragrostis spp. (PP) } & \multicolumn{3}{|l|}{ Type of pollen grain $(\%+S D)$} \\
\hline & & SP & IMP & MP \\
\hline S1 & $67.46 \pm 1.82$ & Cardus spp. (17.85 \pm 0.93$)$ & Phoenix spp. $(9.77 \pm 0.56)+$ Others $(4.93 \pm 0.34)$ & - \\
\hline S2 & $67.97 \pm 1.84$ & Phoenix spp. (22.19 \pm 2.28$)$ & Thymus spp. (7.07 \pm 0.56$)$ & Olea spp. (2.78 \pm 0.11$)$ \\
\hline S3 & $67.55 \pm 2.64$ & Thymus spp. $(19.28 \pm 1.65)$ & Cardus spp. (6.46 \pm 0.49$)+$ Phoenix spp. (6.71 \pm 0.49$)$ & - \\
\hline S4 & $46.58 \pm 1.59$ & $\begin{array}{l}\text { Cardus spp. }(22.39 \pm 0.99)+ \\
\quad \text { Olea spp. } 16.76 \pm 1.45)\end{array}$ & Thymus spp. $(8.06 \pm 0.28)+$ Others $(6.22 \pm 0.85)$ & - \\
\hline S5 & $72.72 \pm 2.43$ & - & $\begin{array}{l}\text { Cardus spp. (14.97 } \pm 0.75)+ \text { Phoenix spp. } \\
\quad(7.34 \pm 0.93)+\text { Thymus spp. }(4.97 \pm 0.75)\end{array}$ & - \\
\hline S6 & $79.67 \pm 1.82$ & - & $\begin{array}{l}\text { Cardus spp. (9.05 } \pm 1.57)+ \text { Thymus spp. } \\
(7.85 \pm 0.13)+\text { Others }(3.44 \pm 0.37)\end{array}$ & - \\
\hline
\end{tabular}

Abbreviations ( $S D=$ standard deviation; $\mathrm{PP}=$ predominant pollen ( $>45 \%)$; $\mathrm{SP}=$ secondary pollen (16-45\%); IMP = important minor pollen (3-15\%); $\mathrm{MP}=$ minor pollen $(<3 \%) ;-=$ absent $)$.

honeys from diverse floral origin (Bettar et al., in press; Diez, Andres, \& Terrab, 2004; Malika, Mohamed, \& Chakib, 2005) or within the $\mathrm{pH}$ range reported by Terrab, Vega-Pérez, Díez, and Heredia (2002). Free acidity ranged from $8.25 \mathrm{mEq} / \mathrm{kg}$ (S5) to $28.65 \mathrm{mEq} / \mathrm{kg}$ (S3). These free acidity values were within the European limits $(<50 \mathrm{mEq} / \mathrm{kg}$ ) (EU Council, 2002). Such low values are important to prevent undesirable fermentation. As for the lactone acidity, it ranged from $7.00 \mathrm{mEq} / \mathrm{kg}$ (S2) to $15.33 \mathrm{mEq} / \mathrm{kg}$ (S5). Total acidity ranged from $20.80 \mathrm{mEq} / \mathrm{kg}$ (S6) to $38.65 \mathrm{mEq} / \mathrm{kg}$ (S3).

Samples S4 and S5 had the highest (0.22\%) and lowest (0.02\%) ash content, respectively (Table 2). Those results correlated, as reported (Feás, Pires, Estevinho, Iglesias, \& Araújo, 2010), the electrical conductivity parameter, and $\mathrm{S} 4$ had the highest value $(792.33 \mu \mathrm{S} / \mathrm{cm})$, while sample S5 had the lowest value $(201.57 \mu \mathrm{S} / \mathrm{cm})$. The values of ash and conductivity were within the range established by the European Community (below $0.6 \%$ and $800 \mu \mathrm{S} / \mathrm{cm}$, respectively [EU Council, 2002]). The relative low ash content is like citrus honey (Aazza, Lyoussi, Antunes, \& Miguel, 2014; Felsner et al., 2004), although great variability had been observed among samples. Despite being in the same floral origin, the variability can be attributed to the different geographical conditions (soil and edafoclimatic characteristics) where hives are located (Almeida-Muradian et al., 2014).

Only sample S1 had the diastase activity (12.42 Shade units/g) higher than the minimum value required by the European legislation (8 Schade units/g), or 3 Schade units/g in the case of citrus honey (EU Council, 2002). In this last case, the level of HMF should not exceed $15 \mathrm{mg} / \mathrm{kg}$, as a maximal tolerable value, whereas in the remaining types of honey, the maximal allowed content of HMF is $40 \mathrm{mg} / \mathrm{kg}$ (Codex Alimentarius, 2001; EU Council, 2002). In almost all the analyzed samples, HMF content was even below the $15 \mathrm{mg} / \mathrm{kg}$, and only S2 and S6 had values of $25.94 \mathrm{mg} / \mathrm{kg}$ and $21.47 \mathrm{mg} / \mathrm{kg}$, respectively, but still below the generally recommended value $(40 \mathrm{mg} / \mathrm{kg}$ ) (Table 2).

Low diastase activities found in the samples may indicate inadequate storage conditions or processing (relative high temperatures), because the enzyme is susceptible to heat. Nevertheless diastase activities are also dependent on the geographic and floral origins of honey samples (Fallico, Arena, Verzera, \& Zappala, 2006). Keeping in mind that in case of citrus honey, low diastase values are accepted, coming to a conclusion on whether the low value measured in the analyzed samples is a characterizing feature of this honey, or if it is a result of inadequate processing cannot be done. In fact, regarding the low HMF values seen in the samples, it can be suggested that the freshness and the adequate storage conditions of the studied samples, strengthen the first hypothesis, as reported for Citrus honey.

The moisture or water content may vary from 15 to $21 \%$ depending on several factors, such as the botanical origin of the honey, the level of maturity reached in the hive, processing techniques and storage conditions (da Silva, Gauche, Gonzaga, \& Costa, 2016); however, high values may permit the growth of molds on the surface of the honey (Mendes, Proença, Ferreira, \& Ferreira, 1998). Therefore, the established legislation fixed the suitable moisture at values below $20 \%$ (EU Council, 2002). In this work, the moisture was close to the permitted in the four samples, and exceeded that limit in two samples (S4 and S5) (Table 3). Higher percentages of moisture had already been reported for Moroccan honeys (Aazza et al., 2014; Diez et al., 2004; Terrab et al., 2002) of diverse floral origins.

Proline is the most abundant amino acid in honey, representing a total of $50-85 \%$ amino acids, and has been used as a criterion of honey ripeness and sugar adulteration with values not lower than $200 \mathrm{mg} / \mathrm{kg}$ (Hermosín, Chicón, \& Cabezudo, 2003; Manzanares, García, Galdón, Rodríguez, \& Romero, 2014). In the analyzed samples, the proline content varied greatly (Table 3) from a minimum of $251.46 \mathrm{mg} / \mathrm{kg}$ in S5 to maximum of $924.98 \mathrm{mg} / \mathrm{kg}$ in S3, respecting so the recommended limit, and being also within the previously reported values for other botanical origin Moroccan honey (Aazza, Lyoussi, Antunes, \& Miguel, 2013, 2014; Hermosín et al., 2003).

Honey color is an indicator of the presence of polyphenols, terpenes and carotenoids (Naab et al., 2008; Wilczyńska, 2014). In addition, the color and the electrical conductivity also give an indication of the botanical origin of honey (Anjos et al., 2015b). In honey samples of 


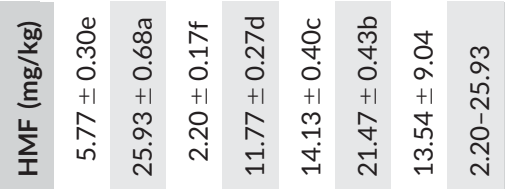

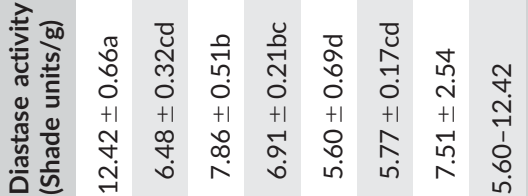

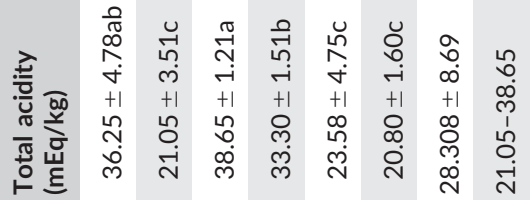

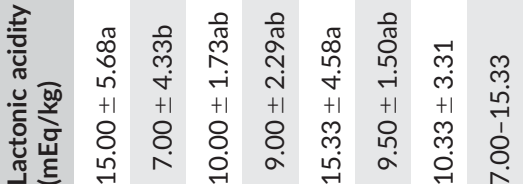

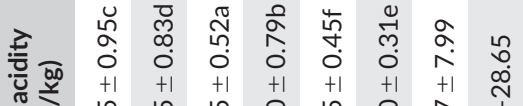

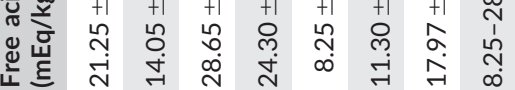

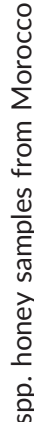

咅

覀

$\frac{x}{4}$

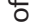

离

$\frac{\sqrt{0}}{\frac{\pi}{\pi}}$

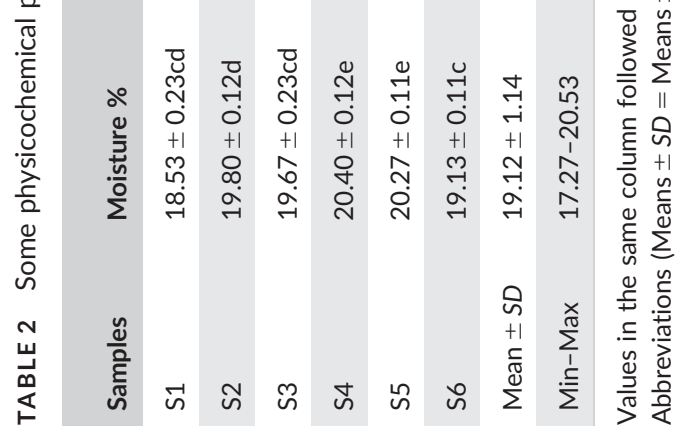

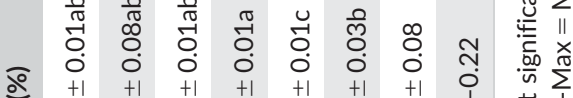

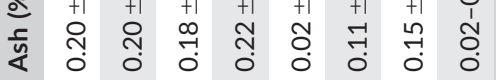

离

童

离

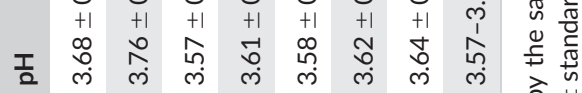

aㅁ

응 $\sum^{\frac{\pi}{\pi}}$

ही

o

恼

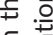

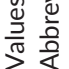

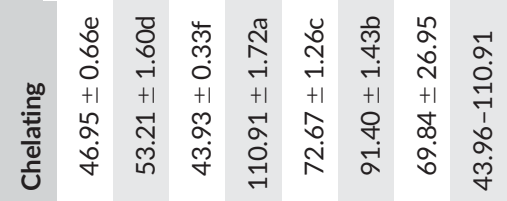

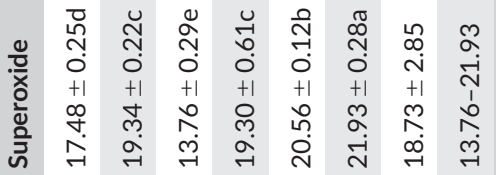

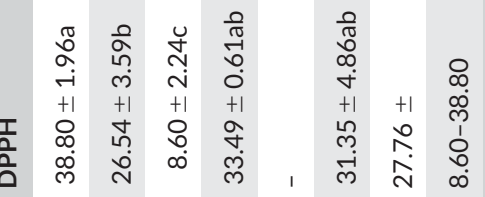

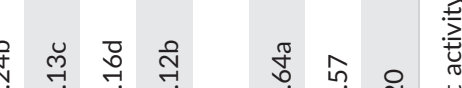

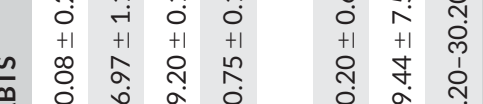

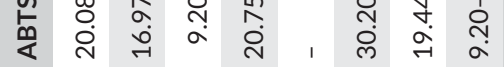

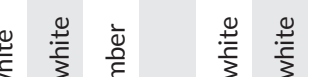

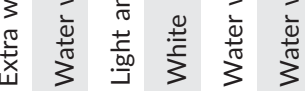

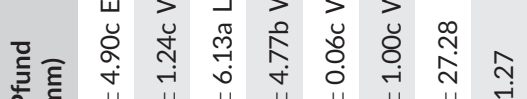

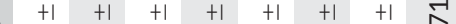

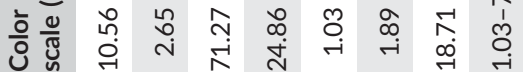

高

हो

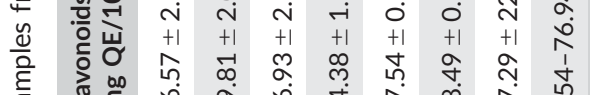

产 西哭

高
항

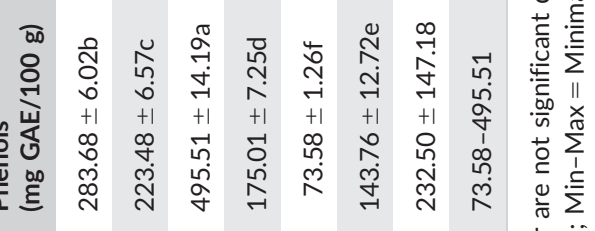

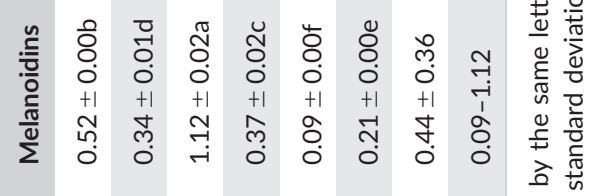

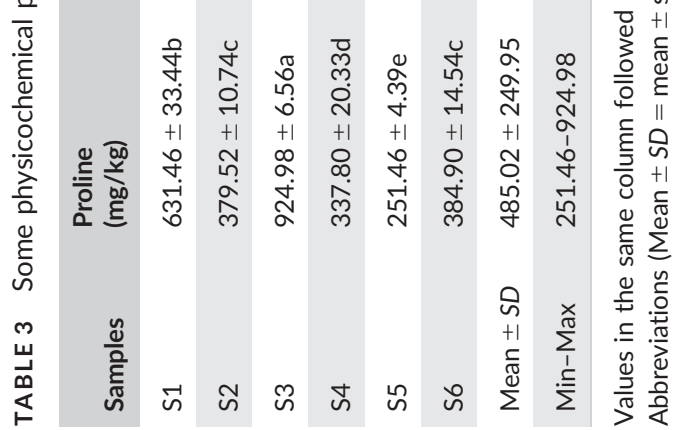


6 of 10 WI LEY \begin{tabular}{ll} 
Journal of & Food Biochemistry \\
\hline
\end{tabular}

TABLE 4 Sugar content (g/100 g) in six Eragrostis spp. honey samples from Morocco

\begin{tabular}{llllll} 
Samples & Fructose & Glucose & Sucrose & Fructose + glucose & Fructose/glucose \\
\hline S1 & $37.8 \pm 0.1 \mathrm{a}$ & $30.7 \pm 0.1 \mathrm{ab}$ & $<0.2$ & $68.5 \pm 0.1 \mathrm{a}$ & $1.2 \pm 0.0 \mathrm{~b}$ \\
S2 & $36.3 \pm 0.4 \mathrm{~b}$ & $36.2 \pm 0.1 \mathrm{~d}$ & $<0.2$ & $72.5 \pm 0.5 \mathrm{ab}$ & $1.0 \pm 0.0 \mathrm{a}$ \\
\hline S3 & $37.0 \pm 0.3 \mathrm{ab}$ & $30.0 \pm 0.1 \mathrm{a}$ & $<0.2$ & $67.0 \pm 0.5 \mathrm{~b}$ & $1.2 \pm 0.0 \mathrm{bc}$ \\
\hline S4 & $38.5 \pm 0.4 \mathrm{~cd}$ & $31.6 \pm 0.0 \mathrm{bc}$ & $<0.2$ & $70.0 \pm 0.4 \mathrm{bc}$ & $1.2 \pm 0.0 \mathrm{~b}$ \\
\hline S5 & $38.5 \pm 0.2 \mathrm{~cd}$ & $30.5 \pm 0.2 \mathrm{a}$ & $<0.2$ & $69.0 \pm 0.4 \mathrm{~cd}$ & $1.3 \pm 0.0 \mathrm{c}$ \\
S6 & $39.2 \pm 0.3 \mathrm{~d}$ & $31.8 \pm 0.5 \mathrm{c}$ & $<0.2$ & $71.9 \pm 0.8 \mathrm{~d}$ & $1.2 \pm 0.0 \mathrm{bc}$ \\
\hline Mean \pm SD & $37.9 \pm 1.1$ & $31.8 \pm 2.2$ & - & $69.7 \pm 1.9$ & $1.2 \pm 0.1$ \\
Min-Max & $36.0-39.4$ & $29.9-36.3$ & - & $66.7-72.9$ & $1.0-1.3$
\end{tabular}

Values in the same column followed by the same letter are not significant different $(p<.05)$ by the Tukey's multiple range test. Abbreviations (Mean $\pm S D=$ Means \pm standard deviation; Min-Max $=$ Minimal-maximal).

the present work, some variability in color, determined at $A_{635}$, was observed: from extra water white (1.03, 1.89, and $2.65 \mathrm{~mm}$ Pfund) in S5, S6, and S2 samples, respectively, to light amber (71.27 $\mathrm{mm}$ Pfund) in S3 (Table 3).

Total polyphenol content varied from $73.58 \mathrm{mg}$ GAE/kg (S5) to $495.51 \mathrm{mg} \mathrm{GAE} / \mathrm{kg}$ (S3) in honey samples. Flavonoid content ranged from $7.54 \mathrm{mg} \mathrm{CE} / \mathrm{kg}$ (S5) to $76.94 \mathrm{mg}$ CE/ $\mathrm{kg}$ (S3) (Table 3). The values of phenols and flavonoids in these honey samples were within the range found for other monofloral Moroccan honeys Aazza et al. (2014), with the exception of sample $\mathrm{S} 5$ that had significantly lower amounts, although close to those found by the same authors for Portuguese honeys (Aazza et al., 2013). Several studies have detected that polyphenol amounts in honey depend on its floral (Escuredo, Míguez, Fernández-González, \& Seijo, 2013; Küçük et al., 2007) and its geographical origins (Rodríguez, Mendoza, Iturriga, \& Castaño-Tostado, 2012; Rosa et al., 2011).

The same variability among the analyzed samples was observed also in melanoidin content, and the values ranged from 0.09 for sample S5 and 1.12 for sample S3 (Table 3). Melanoidins, Maillard reaction products, are multicomponent polymers consisting of proteinpolyphenol-oligosaccharide complexes and phenols, which can be measured at two wavelengths $\left(A_{560}-A_{720}\right)$. They possess several biological properties, such as antioxidant activity (Brudzynski \& Miotto, 2011; Moussa, Saad, \& Noureddine, 2012).

The total fructose and glucose content present in the honey samples ranged from $67.0 \%$ in S3 to $72.5 \%$ in S2 (Table 4). These results are in accordance with those reported by other authors for honey samples from Morocco with different floral origin (Aazza et al., 2014) or from other regions (Aazza et al., 2013; Anjos, Campos, et al., 2015; Shin \& Ustunol, 2005). In addition, and according to the results obtained, all the samples had the minimal concentrations required for blossom honeys (>60\%) (Codex Alimentarius, 2001).

All the samples have higher amounts of fructose than glucose, however, one sample (S2) had practically the same amount of both. Codex Alimentarius (2001) established 5\% as maximal limit for sucrose in honey, which was the case of the analyzed samples, with values below $0.2 \%$.

Table 5 depicts the concentration of some minerals present in honey samples from Morocco. The total mineral content was always
$<1 \%(0.3-0.8 \%)$, with potassium present in higher amounts in practically all samples with the exception of sample S6, in which Na prevailed (Table 5). The percentages of potassium ranged from $49.34 \mathrm{mg} / \mathrm{kg}$, in $\mathrm{S} 6$, to $607.24 \mathrm{mg} / \mathrm{kg}$, in $\mathrm{S} 1$. Calcium and sodium were quantitatively the second most representative minerals in the samples. Sample S4 showed the highest concentrations of calcium and sodium (188.02 and $252.25 \mathrm{mg} / \mathrm{kg}$, respectively). Magnesium was the fourth most abundant, with S4 presenting the highest concentration $(30.32 \mathrm{mg} / \mathrm{kg})$. The most elevated amounts of iron were found in samples $\mathrm{S} 1(6.92 \mathrm{mg} / \mathrm{kg})$ and S5 $(5.38 \mathrm{mg} / \mathrm{kg})$. Zinc and copper, and particularly manganese were in lower amounts in all the samples when compared to the remaining mineral reported earlier. All the data is within the values generally reported for honey samples (Solayman et al., 2016 and references therein). Usually the variability in the individual amounts of minerals in the analyzed honey samples can be attributed to differences in floral type and soil composition (Solayman et al., 2016).

However, in this work the variability seen in almost all the analyzed parameters cannot be explained by the variability of the Eragostis spp. pollen ratios, suggesting its small nectar production or the nectar in itself is diluted nectar. This feature may question the monoflorality of those samples, and suggest the need of more pollen percentage to have the monofloral label.

\section{3 | Antioxidant activity}

The antioxidant activities of the honey samples were measured using five different methods: three assays assessed the capacity for scavenging free radicals (DPPH, ABTS, and superoxide), one assay assessed the capacity for chelating metal ions, and lastly one assay that determined the capacity of samples for reducing Fe(III) to Fe(II), in the test known as reducing power. The results are shown in Table 3 and Figure 1.

Sample 3 (S3) always had lower $I C_{50}$ values than the remaining samples, independent on the method used, which indicates that it has the best capacity for scavenging free radicals and chelating metal ions. The capacity for reducing Fe(III) to Fe(II) is also better for S3 (Figure 1). In contrast, S5 was unable to scavenge ABTS and DPPH free radicals, at least at the concentrations assayed. 


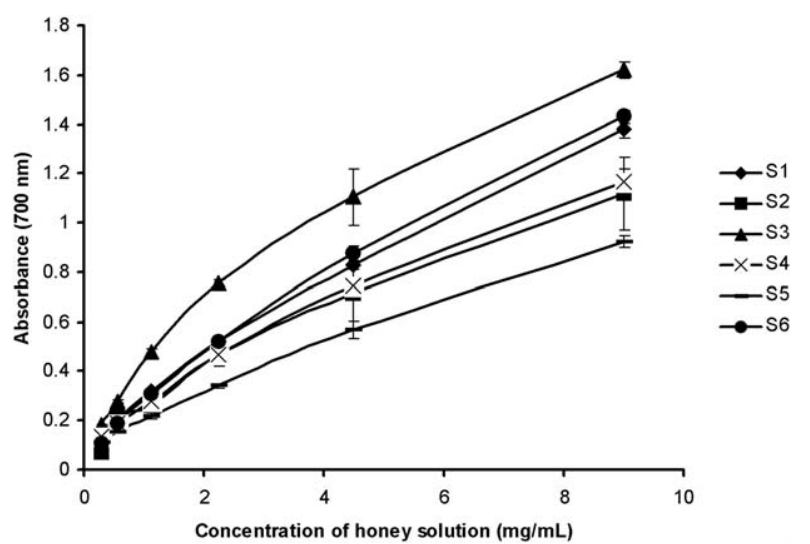

FIGURE 1 The reducing power of honey samples

In general, the antioxidant activity of honey samples depends on the honey floral origin, due to the differences in the content of polyphenolics and enzyme activities (Alvarez-Suarez et al., 2010, 2013; Sousa et al., 2016). However, differences in the activities and the polyphenol content were already reported by Aazza et al. (2014) for the several monofloral thyme honeys and monofloral jujube honeys from Morocco. The authors attributed such results to the different geographic origins from where samples had been collected. In the present work, the geographic origin is the same; nevertheless, differences were detected in the antioxidant activity as well as in other parameters already discussed above. Such results indicate that even in the same region, honeybees of diverse beekeepers have different plants available to visit. Melissopalynological analysis gave us this information (Table 1). Furthermore, the variability observed in the grain pollen of Eragrostis spp. does not explain the variability seen in the antioxidant activity results, suggesting the hypothesis that this honey type needs more Eragrostis spp. pollen percentage to be labeled as monofloral honey.

A negative correlation between total polyphenols, proline amounts, and $\mathrm{IC}_{50}$ values (Table 6 ) determined when analyzing the capacity for scavenging free radicals, demonstrates the importance of these compounds on the found activity. The correlation between polyphenols and antioxidant activity was previously reported (Aazza et al., 2013, 2014; Alvarez-Suarez et al., 2010). The negative correlation between $\mathrm{IC}_{50}$ values and proline content may reveal an important role of this amino acid on the capacity for scavenging free radicals. Antioxidant activity of some amino acids (histidine, taurine, glycine, alanine, proline) has been reported (Meda, Lamien, Romito, Millogo, \& Nacoulma, 2005; Wu, Shiau, Chen, \& Chiou, 2003).

A positive correlation between color and antioxidant activity and a negative correlation between melanoidin and antioxidant activity (Table 6) were also observed in the present work and also previously reported (Aazza et al., 2014), in Morrocan honeys of different floral origins.

An overview made by some authors (Maurya, Kushwaha, Singh, \& Singh, 2014) on antioxidant activity of honeys from different flora and geographical origins showed a great variability in the abilities for scavenging DPPH and ABTS free radicals. The capacity for scavenging ABTS free radicals by Portuguese honeys, independent on the floral origin, was superior to those of the present work (Aazza et al., 2013). 


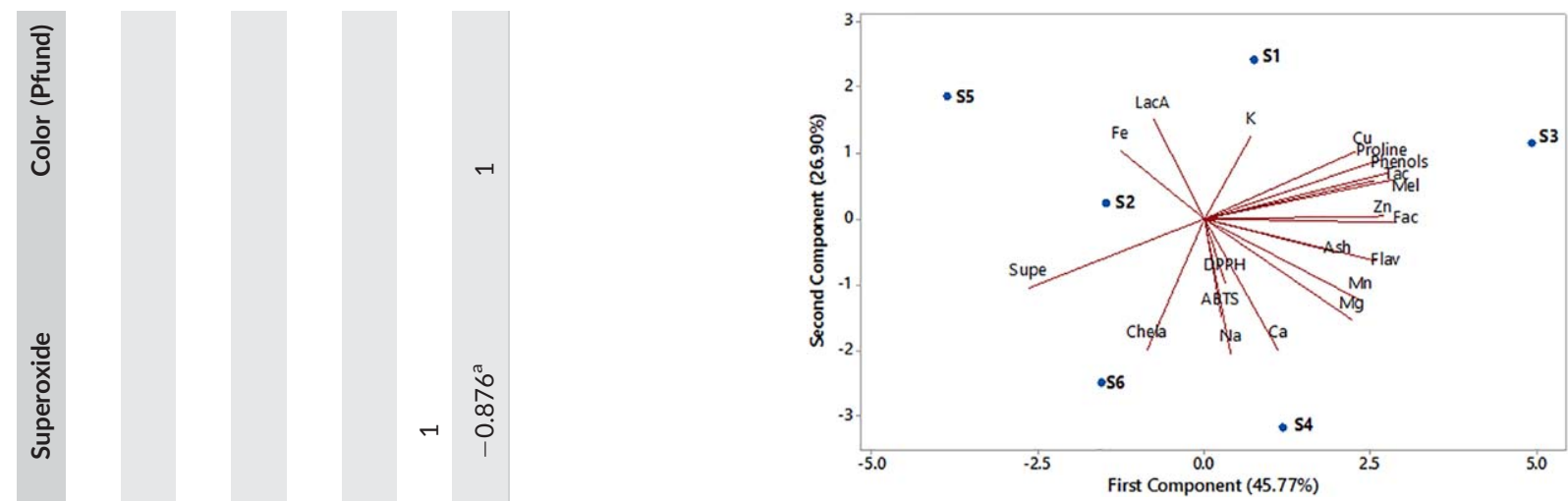

FIGURE 2 Scatterplot of honey samples and measured parameters on the plane defined by the two first components of principal component analysis.

Note. ash $=$ ash content; FAC $=$ free acidity; $\mathrm{LACA}=$ lactonic acidity; TAC = total acidity; PROLINE = proline content; $\mathrm{MEL}=$ melanoidins; PHENOLS $=$ phenols content; $\mathrm{FLA}=$ flavonoids content; $A B T S=A B T S$ radical scavenging; $D P P H=D P P H$ free radicals; $\mathrm{SUPE}=$ superoxide; $\mathrm{CHEL}=$ chelating; mineral content = Ca; Na; Mg; K; Fe; Zn; Cu; Mn

The values found in the present work were within the range detected for Moroccan honeys, regardless of the floral origin (Aazza et al., 2013). Since the methodology followed in all assays was the same because they were performed by the same team in the same laboratory, we can conclude that for the same floral origin of honeys, the geographical origin has a very important role on the antioxidant activity. Such is in accordance to that observed in the present work: for the same floral origin of honeys (predominance of Eragrostis spp. pollen), diverse activities were found.

\section{4 | Variance explained by principal component analysis}

The data of all measured parameters were subjected to the principal component analysis (PCA). As a first step, all the variables were used to run the PCA (data not showed), and only the variables correlating the resulted factors with, at least, 0.7 as second step were chosen. The results are shown in the Figure 2, where the first two principal components accounted for $72.7 \%$ of the total variance, however, in the third component (total of $87.3 \%$ ) the content of $\mathrm{K}$ and Fe with the DPPH free radicals correlated well.

The plot of the honey samples in the plane defined by the two components exhibits the separation of all samples reported a variability between samples. The first component split into two groups (Group 1: S2, S5, and S6; Group 2: S1, S3, and S4). The second component which accounted for $26.9 \%$ of the total variance, separated samples S4 and S6 from the others. In fact, the two components are responsible for different groups of characteristics of honey. Component 1 correlated well the ash content, acidity, proline, melanoidins, phenols, and flavonoids content and the minerals $\mathrm{Mg}, \mathrm{Zn}, \mathrm{Cu}$, and $\mathrm{Mn}$ together and superoxide in inverse order. The sample S3 was characterized by a higher amount in these components (Figure 2). 
Component 2 correlated well ABTS, chelating, $\mathrm{Ca}$ and $\mathrm{Na}$ and in inverse order the lactonic acidity. Samples $\mathrm{S} 1$ and $\mathrm{S} 5$ have an important amount of $\mathrm{K}$ and $\mathrm{Fe}$ and S4 and S6 have the higher values of ABTS and DPPH.

\section{4 | CONCLUSIONS}

The analyzed samples showed great variability in their physicochemical parameters, and antioxidant profiles, independently on the high representability of Eragrostis spp. pollen species. The changes in the analyzed parameters seem to be more sensitive to the secondary important pollen species, suggesting that the melliferous plant Eragrostis spp. is a weak nectar delivering plants. In addition, to eliminate the hypothesis of other possible influencing factors (meteorological) on nectar secretion, further work needs to be carried out on several apicultural season samples.

Approaching this honey type for possible industrial or medicinal uses seems to be delicate, and high attention needs to be payed to secondary important pollen, and if possible apply a preliminary tool to assess its antioxidant activity.

\section{ACKNOWLEDGMENTS}

The authors thank to the Centro de Apoio Tecnológico Agro-Alimentar de Castelo Branco (CATAA) for the equipment availability for sugar determination. The authors would like to express their gratitude to Isabele Salavessa (IPCB Languages centre) for the English revision. The research unit Centro de Estudos Florestais is supported by the Portuguese National Funding Agency for Science, Research and Technology (Fundação para a Ciência e a Tecnologia - FCT), projects UID/AGR/00239-2013, UID/BIA/04325/2013 - MEDTBIO, UID/ Multi/04326/2013 and UID/BIA/04050/2013.

\section{CONFLICT OF INTEREST}

The authors declare no potential conflicts of interest with respect to the research, authorship, and/or publication of this article.

\section{ORCID}

Ofélia Anjos (D) http://orcid.org/0000-0003-0267-3252

Maria G. Miguel (D) http://orcid.org/0000-0003-2507-4228

\section{REFERENCES}

Aazza, S., Lyoussi, B., Antunes, D., \& Miguel, M. G. (2013). Physicochemical characterization and antioxidant activity of commercial Portuguese honeys. Journal of Food Science, 78, 1159-1165.

Aazza, S., Lyoussi, B., Antunes, D., \& Miguel, M. G. (2014). Physicochemical characterization and antioxidant activity of 17 commercial Moroccan honeys. International Journal of Food Science Nutrition, 65, 449-457.

Almeida-Muradian, L. B., Stramm, K. M., \& Estevinho, L. M. (2014). Efficiency of the FT-IR ATR spectrometry for the prediction of the physicochemical characteristics of Melipona subnitida honey and study of the temperature's effect on those properties. International Journal of Food Science Technology, 49, 188-195.
Alvarez-Suarez, J. M., Giampieri, F., \& Battino, M. (2013). Honey as a source of dietary antioxidants: Structures, bioavailability and evidence of protective effects against human chronic diseases. Current Medicinal Chemistry, 20, 621-638.

Alvarez-Suarez, J. M., Tulipani, S., Díaz, D., Estevez, Y., Romandini, S., Giampieri, F., ... Battino, M. (2010). Antioxidant and antimicrobial capacity of several monofloral Cuban honeys and their correlation with color, polyphenol content and other chemical compounds. Food Chemical Toxicology, 48, 2490-2499.

Anjos, O., Campos, M. G., Ruiz, P. C., \& Antunes, P. (2015). Application of FTIR-ATR spectroscopy to the quantification of sugar in honey. Food Chemistry, 169, 218-223.

Anjos, O., Iglesias, C., Peres, F., Martínez, J., García, A., \& Taboada, J. (2015). Neural networks applied to discriminate botanical origin of honeys. Food Chemistry, 175, 128-136.

Bettar, I. M., González-Miret, L., Hernanz, D., Marconi, A., Heredia, F. J., \& Terrab, A. (in press). Characterisation of Moroccan Spurge (Euphorbia) honeys by their physicochemical characteristics, mineral contents and colour. Arabian Journal of Chemistry, http://dx.doi.org/10.1016/j. arabjc.2015.01.003

Bogdanov, S. (2002). Harmonized methods of the international honey commission. Retrieved from http://www.apiculturacluj.com/ApiculturaCluj/ italiano/Documents/IHCmethods_e.pdf

Brand-Williams, W., Cuvelier, M. E., \& Berset, C. (1995). Use of free radical method to evaluate antioxidant activity. Lebensmittel-Wissenschaft \& Technologie, 28, 25-30.

Brudzynski, K., \& Miotto, D. (2011). The recognition of high molecular weight melanoidins as the main components responsible for radicalscavenging capacity of unheated and heat-treated Canadian honeys. Food Chemistry, 125, 570-575.

Codex Alimentarius. (2001). Revised Codex standard for Honey, Codex STAN 12-1981, revisions 1987 and 2001.

da Silva, R. M., Gauche, C., Gonzaga, L. V., \& Costa, A. C. O. (2016). Honey: Chemical composition, stability and authenticity. Food Chemistry, 196, 309-232.

Diez, M. J., Andres, C., \& Terrab, A. (2004). Physicochemical parameters and pollen analysis of Moroccan honeydew honey. International Journal of Food Science and Technology, 39, 167-176.

Elamine, Y., Aazza, S., Lyoussi, B., Antunes, M. D., Estevinho, L. M., Anjos, O., ... Miguel, M. G. (2017). Preliminary characterization of a Moroccan honey with a predominance of Bupleurum spinosum pollen. Journal of Apicultural Research, https://doi.org/10.1080/00218839. 2016.1265759

El-Sohaimy, S. A., Masry, S. H. D., \& Shehata, M. G. (2015). Physicochemical characteristics of honey from different origins. Annals of Agricultural Science, 60, 279-287.

Escuredo, O., Míguez, M., Fernández-González, M., \& Seijo, M. C. (2013). Nutritional value and antioxidant activity of honeys produced in an European Atlantic area. Food Chemistry, 138, 851-856.

EU Council. (2002). Council directive 2001/11 O/EC of 20 December 2001 relating to honey. Official Journal of European Communities, 10, 47-52.

Fallico, B., Arena, E., Verzera, A., \& Zappala, M. (2006). The European food legislation and its impact on honey sector. Accreditation and Quality Assurance, 11, 49-54.

Feás, X., Pires, J., Estevinho, M. L., Iglesias, A., D. E., \& Araújo, J. P. P. (2010). Palynological and physicochemical data characterization of honeys produced in the Entre-Douro e Minho region of Portugal. International Journal of Food Science \& Technology, 45, 1255-1262.

Felsner, M. L., Cano, C. B., Bruns, R. E., Watanabe, H. M., AlmeidaMuradian, L. B., \& Matos, J. R. (2004). Characterization of 
monofloral honeys by ash contents through a hierarchical design. Journal of Food Composite Analysis, 17, 737-747.

Gomes, S., Dias, L. G., Moreira, L. L., Rodrigues, P., \& Estevinho, L. (2010). Physico-chemical, microbiological and antimicrobial properties of commercial honeys from Portugal. Food Chemical Toxicology, 48, 544-548.

Hermosín, I., Chicón, R. M., \& Cabezudo, M. D. (2003). Free amino acid composition and botanical origin of honey. Food Chemistry, 83, 263-268.

Küçük, M., Kolayl, S., Karaoglu, S., Ulusoy, E., Baltac, C., \& Candan, F. (2007). Biological activities and chemical composition of three honeys of different types from Anatolia. Food Chemistry, 100, 526-534.

Louveaux, J., Maurizio, A., \& Vorwohl, G. (1978). Methods of melissopalinology. Bee World, 59, 139-157.

Malika, N., Mohamed, F., \& Chakib, E. A. (2005). Microbiological and physico-chemical properties of Moroccan honey. International Journal of Agricultural Biology, 5, 773-776.

Manzanares, A. B., García, Z. H., Galdón, B. R., Rodríguez, E. R., \& Romero, C. D. (2014). Physicochemical characteristics of minor monofloral honeys from Tenerife, Spain. LWT - Journal of Food Science Technology, 55, 572-578.

Maurya, S., Kushwaha, A. K., Singh, S., \& Singh, G. (2014). An overview on antioxidative potential of honey from different flora and geographical origins. Indian Journal of National Productive Research, 5, 9-19.

Meda, A., Lamien, C. E., Romito, M., Millogo, J., \& Nacoulma, O. G. (2005). Determination of the total phenolic, flavonoid and proline contents in Burkina Fasan honey, as well as their radical scavenging activity. Food Chemistry, 91, 571-577.

Mendes, E., Proença, E. B., Ferreira, I. M. P. L. V. O., \& Ferreira, M. A. (1998). Quality of evaluation of Portuguese honey. Journal of Carbohydrates Polymer, 37, 219-223.

Miguel, M. G., Nunes, S., Dandlen, S. A., Cavaco, A. M., \& Antunes, M. D. (2010). Phenols and antioxidant activity of hydro-alcoholic extracts of propolis from Algarve, South of Portugal. Food and Chemical Toxicology, 48, 3418-3423.

Moujanni, A., Essamadi, A. K., \& Terrab, A. (2017). L'apiculture au Maroc: Focus sur la production de miel. Beekeeping in Morocco: Focus on honey production. International Journal of Innovative Applied Studies, 20, 52-78.

Moussa, A., Saad, A., \& Noureddine, D. (2012). How honey acts as an antioxidant?. Medicinal \& Aromatic Plants, 1, e121. https://doi.org/10. 4172/2167-0412.1000e121

Naab, O. A., Tamame, M. A., \& Caccavari, M. A. (2008). Palynological and physico-chemical characteristics of three unifloral honey types from central Argentina. Spanish Journal of Agricultural Research, 6, 566-576.

Proposal COM/95/0722. (1996, August 9). Amendments to prior Council Directive relating to honey (COM(95)0722 - C4-0403/96 - 96/0114 (CNS)), European Parliament, 9th December, 1997.

Rao, P. V., Salleh, N., \& Gan, S. H. (2016). Biological and therapeutic effects of honey produced by honey bees and stingless bees: a comparative review. Brazilian Journal of Pharmacognosy, 26, 657-664.

Rodríguez, B. A., Mendoza, S., Iturriga, M. H., \& Castaño-Tostado, E. (2012). Quality parameters and antioxidant and antibacterial properties of some Mexican honeys. Journal of Food Science, 71, 121-127.

Rosa, A., Tuberoso, C. I. G., Atzeri, A., Melis, M. P., Bifulco, E., \& Dessì, M. A. (2011). Antioxidant profile of strawberry tree honey and its marker homogentisic acid in several models of oxidative stress. Food Chemistry, 129, 1045-1053.

Sakanaka, S., \& Ishihara, Y. (2008). Comparison of antioxidant properties of persimmon vinegar and some other commercial vinegar in radicalscavenging assays and on lipid oxidation in tuna homogenates. Food Chemistry, 107, 739-744.

Samatha, T., Shyamsundarachary, R., Srinivas, P., \& Swang, N.,R. (2012). Quantification of total phenolic and total flavonoid contents in extracts of Oroxylum indicum L. Kurz Asian Journal of Pharmaceutical and. Clinical Research, 5, 177-179.

Sancho, M. T., Pascual-Maté, A. N. A., Rodríguez-Morales, E. G., Osés, S. M., Escriche, I., Periche, Á., \& Fernández-Muiño, M. A. (2016). Critical assessment of antioxidant related parameters of honey. International Journal of Food Science \& Technology, 51, 30-36.

Shin, H.-S., \& Ustunol, Z. (2005). Carbohydrate composition of honey from different floral sources and their influence on growth of selected intestinal bacteria: An in vitro comparison. Journal of Food Research International, 38, 721-728.

Silva, T. M. S., Dos Santos, F. P., Evangelista-Rodrigues, A., da Silva, E. M. S., da Silva, G. S., de Novais, J. S., \& Camara, C. A. (2013). Phenolic compounds, melissopalynological, physicochemical analysis and antioxidant activity of jandaíra (Melipona subnitida) honey. Journal of Food Composites Analysis, 29, 10-18.

Singleton, V. L., \& Rossi, J. A. Jr. (1965). Colorimetry of total phenolics with phosphomolybdic-phosphotungstic acid reagents. American Journal of Enology Viticulture, 16, 144-158.

Soares, J. R. A. S. (1996). Constituição polifenólica e actividade antioxidante de extractos de Thymus zygis (Master's thesis). Universidade de Coimbra, Coimbra.

Solayman, Md., Islam, Md., Paul, S., Ali, Y., Khalil, Md., Alam, N., \& Gan, S. H. (2016). Physicochemical properties, minerals, trace elements, and heavy metals in honey of different origins: A comprehensive review. Comprehensive Reviews in Food Science and Food Safety, 15, 219-233.

Sousa, J. M., DE Souza, E. V., Marques, G., Meireles, B., Cordeiro, A. T. M., Gullón, B., ... Magnani, M. (2016). Polyphenolic profile and antioxidant and antibacterial activities of monofloral honeys produced by Meliponini in the Brazilian semiarid region. Journal of Food Research International, 84, 61-68.

Terrab, A., Vega-Pérez, J. M., Díez, M. J., \& Heredia, F. J. (2002). Characterisation of northwest Moroccan honeys by gas chromatographic-mass spectrometric analysis of their sugar components. Journal of the Science of Food and Agriculture, 82, 179-185.

Wilczyńska, A. (2014). Effect of filtration on colour, antioxidant activity and total phenolics of honey. Journal of Food Science Technology, 57, 767-774.

Wu, H. C., Shiau, C. Y., Chen, H. M., \& Chiou, T. K. (2003). Antioxidant activities of carnosine, anserine, some free amino acids and their combination. Journal of Food Drug Analysis, 11, 148-153.

How to cite this article: Aazza S, Elamine Y, El-Guendouz S, et al. Physicochemical characterization and antioxidant activity of honey with Eragrostis spp. pollen predominance. J Food Biochem. 2018;42:e12431. https://doi.org/10.1111/jfbc.12431 